\title{
Efeito da contagem de folículos antrais na seleção de doadoras e produção de embriões in vitro em vacas da raça Nelore
}

Sheila Merlo Garcia, Paula Alvares Lunardelli, Amanda Fonseca Zangirolamo, Aline de Oliveira Santos, Claudia Maria Bertan Membrive, Caliê Castilho, Raquel Zaneti Puelker, José Otávio Folino Silva, Marcelo Marcondes Seneda’

Laboratório de Biotecnologia da Reprodução Animal, Departamento de Clínicas Veterinárias, Universidade Estadual de Londrina (UEL), Londrina, PR, Brasil

*Autor correspondente

e-mail: marcelo.seneda@gmail.com

\section{Resumo}

A busca por alternativas que otimizem a produtividade do rebanho faz-se de suma importância no cenário da pecuária nacional e mundial. Nesse contexto, diversos estudos relatam que a contagem de folículos antrais (CFA) está associada com parâmetros de fertilidade do rebanho bovino e, por sua vez, pode ser uma importante ferramenta na escolha de doadoras com alto potencial de produção de embriões in vitro (PIVE). Todavia, alguns grupos de pesquisa têm apresentado resultados controversos. Assim sendo, o objetivo deste estudo foi avaliar o efeito da alta e baixa CFA de vacas doadoras da raça Nelore (Bos indicus) na produção in vitro de embriões. Para isso, foi feita a classificação de femêas com idade entre 24 e 36 meses em vacas de alta CFA (entre 23-40 folículos, $n=8$ ), e vacas de baixa CFA (ente 6-12 folículos, $\mathrm{n}=8$ ). Todas as vacas foram previamente sincronizadas, cinco dias depois submetidas à OPU, e os oócitos aspirados foram posteriormente utilizados para PIVE. Fez-se a avaliação dos embriões produzidos no terceiro dia após a inseminação para se determinar a taxa de clivagem e seguiu-se no sétimo e décimo dia a avaliação da taxa de blastocisto. Os dados resultantes foram considerados não paramétricos, analisados pelo teste de Kruskal-Wallis para amostras independentes, com nível de significância de 1\%, e as porcentagens pelo teste de qui-quadrado, com nível de significância de 5\%. Um total de 1445 oócitos foram aspirados de vacas de alta CFA e 381 oócitos de vacas de baixa CFA. 0 grupo de alta CFA obteve maiores médias de oócitos aspirados/OPU (30,1 $\pm 14,9$ vs. 7,9 \pm 3,8; $\mathrm{P}<0,01)$, oócitos cultivados/OPU $(24,6 \pm 12,3$ vs. 5,9 $\pm 2,8 ; \mathrm{P}<$ 0,01), embrião clivado/OPU (19,8 $\pm 9,7$ vs. 4,46 $\pm 2,37)$, blastocistos no D7/OPU (9,7 $\pm 6,4$ vs. 1,5 $\pm 1,6$; P< $0,01)$ e blastocistos no D10/OPU (10,3 $\pm 6,5$ vs. 1,7 $\pm 1,8$; $\mathrm{P}<0,01)$ quando comparado ao grupo de baixa CFA. Não houve diferença na porcentagem de clivagem em relação aos oócitos cultivados presentes nos dois grupos $(80,4 \%$ vs. 75,6\%; P < 0,01), no entanto, as porcentagens de blastocistos no D7 e no D10 dos oócitos 
cultivados no grupo de alta CFA $(39,8 \%$ e $41,8 \%$, P $<0,01)$ foram superiores ao grupo com baixa CFA $(26,1 \%$ e 29,0\%, P < 0,01). Por fim, foi possível concluir que a CFA em vacas da raça Nelore está associada a melhores taxas de PIVE. 